\title{
Original article \\ DEPRESSION AND ASSOCIATED FACTORS AMONG TEA GARDEN WORKERS OF SELECTED TEA GARDEN IN SYLHET
}

\author{
Iffat Nowshin', Mahmuda Ahmed ${ }^{2}$,Shahria Sattar ${ }^{3}$
}

\begin{abstract}
Background: Tea garden workers play a crucial role to the economy of the country. Majority of the tea garden worker are females and suffer from various health problems including depression. The study was conducted to assess the extent of depression among the tea garden workers and their associated factors.

Methods: This descriptive type of cross-sectional study was conducted among 192 respondents in a selected tea garden name Jaflong tea garden in Goainghat, Sylhet. An interview was conducted face to face with the respondents for data collection with a semi-structured questionnaire. To assess the depression, the respondents were at first screened by General Health Questionnaire 12 and then who scored more than 2 were clinically assessed by Diagnostic and statistical manual fourth edition(DSM-4). After then Hamilton Rating scale for depression (HRDS) was used to measure the severity of depression among the diagnosed depressed cases. The study was conducted at Jaflong tea garden in Goainghat, Sylhet. The study period extended from September 2015 to February 2016.

Results: The results show about two third of the respondents were distributed in the age group 30-40 years. Out of the total 192 respondents 72 were male (37\%) and 120 were female (63\%). About four-fifth (80\%) of the respondents were illiterate compared to only $20 \%$ respondents who had primary level education and all the respondents were inhabitant of slum. The monthly family income of the respondents was from 900 taka to 2500 taka. Among the total 192 respondents, $78(40.7 \%)$ had a working experience of 16-21 years followed by $62(32.3 \%)$ had 10-15 years and 52 $(27 \%)$ had $4-9$ years. Almost $80 \%$ of the respondents $(n=152)$ worked for 8 hours. The proportion of depression among the particular tea garden workers were $21 \%$. Altogether 40 respondents (out of 192) were found as patient of depression and the prevalence rate is more in ever married women of less than or equal to 35 years old and whose experience is 16-21 years and have to work more than or equal to 8 hours.
\end{abstract}

Conclusion: Workers with a potential to suffer from depression may be a crucial economic problem for employers. So from the present study, it is highlighted that mental illness is a significant public health problem in particular occupational sector that need to be addressed to the concerned people.

JOPSOM 2020; 39(2): 14-19

https://doi.org/10.3329/jopsom.v39i2.53161

Keywords: Depression, Psychiatric illness, Job satisfaction, Working experience.

1. Associate Professor, Department of Community Medicine, Shaheed Monsur Ali Medical College, Uttara, Dhaka-1230.

2. Assistant Professor, Department of Community Medicine, East-West Medical College, Aichi Nagar, Turag, Dhaka-1711.

3. Assistant Professor, Department of Occupational \& Environmental Health, NIPSOM, Mohakhali, Dhaka1212.

Correspondence: Dr. Iffat Nowshin. E-mail-drnowshin@yahoo.com

\section{INTRODUCTION}

Tea is an important export item in Bangladesh. Bangladesh ranks tenth among the ten largest teaproducing and exporting countries in the world. In the year 2000 , the country's tea production was $1.80 \%$ of the 2,939.91 million kg produced worldwide. Most of the 163 tea estates in Bangladesh are located in the
North-eastern region of Bangladesh-Maulvi Bazar, Hobiganj, Sylhet, Brahmanbaria districts. There are a few number of tea estates in Panchagar District and in Chittagong, a South-eastern district. Owners of tea gardens include both foreign and local companies. ${ }^{1}$

Among the labour forces majority of the tea garden worker are female. Housekeeping and child rearing are 
the traditionally accepted roles of an adult female in our society and a large number of women working in the industrial field have added a new milestone in our national progress. Though much social stigma and orthodox attitudes are still prevailing in our society. All over the world, there is growing interest in studying the effect of increasing specific division of labour on the emotional quality of our lives.

The psychological stressor is literally a creation of the human brain which perceives information as challenging to its own coping ability. Many situational and individual factors limit this coping ability. Depression can affect men and women of any age, education, economic or social status and it affects people in their working age. When depressed employees go undetected and untreated, their symptoms can have more of an organizational impact. This can cause lower productivity, increased absenteeism, increased medical costs, increased disability costs and claims, poor work performance, poor morale and increased job dissatisfaction among other workers. Usual signs of depression in the work places are arriving late for work or absent, losing interest in work, lowered productivity behaving out of character, having difficulty cooperating with coworkers. $^{2}$

An important observation is that screening for common mental disorders is probably pointless because of the rapid change in illness status, the number of persons having problems may overwhelm the occupational health service and the predictive value is low and suggested various factors influence psychiatric service utilization such as unawareness and stigma. $^{3}$

Tea is one of the major cash crops of Bangladesh earned by tea garden workers. But unfortunately the workers of these tea gardens live a sub human life. They are all landless and livings in tea garden's slums. They are mostly illiterate and unaware about their health needs. They contribute much to national economy in respect of earning foreign currency ${ }^{4}$. A study shown at any onetime 1 in 20 employees experience depression which adversely affects a person's work life. Major depression accounts for nearly half of the nation's excess lost productive time, workers with depression also loss significantly more time due to ill health than non-depressed workers. Such lost time is estimated to cost the country billions of dollars each year. ${ }^{5}$

The aim of this present study is to assess depressive disorders in this population group and look for the factors associated with these problems. This may in turn create awareness about the occurrence of such illness among the concerned people.

\section{METHODS}

A cross sectional descriptive study was conducted to assess the extent of depression among the workers in a selected tea garden. The study period extended from September 2015 to February 2016. The respondents were taken from the Jaflong tea garden in Goainghat, Sylhet. Among them 192 workers were willing to participate in the study. Data were collected by face to face interview with the help of a semi-structured questionnaire. To assess the depression, the respondents were at first screened by screening tool of General Health Questionnaire $12^{6}$ and then who scored more than 2 were clinically assessed by Diagnostic and statistical manual fourth edition(DSM-4) ${ }^{7}$ criteria which is subsequently confirmed by consultant psychiatrist. After then Hamilton Rating scale for depression (HRDS $)^{8}$ was used to measure the severity of depression among the diagnosed depressed cases.

All data were cleaned considering the nature of variables and maintaining quality control check. Data were processed by editing, coding and categorization and preserved by marinating confidentiality.

\section{RESULTS}

In this cross-sectional type of study, the findings were organized according to socio-demographic characteristics of the workers, the proportion of workers having depression and the extent of depression among the study population in workplace.

About two third of the respondents were distributed in the age group 30-40. Out of the total 192 respondents 72 were male (37\%) and 120 were female (63\%) and all the respondents were slum dwellers. About fourfifth $(80 \%)$ of the respondents were illiterate and rest $(20 \%)$ of the respondents were educated only up to primary level (Fig-1).

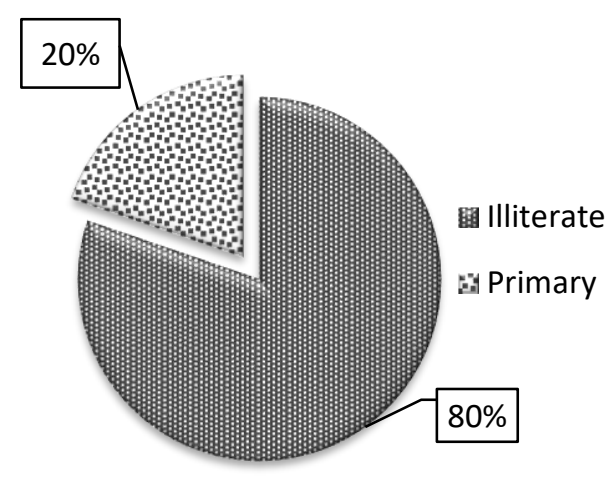

Figure 1: Distribution by educational qualification 
About $73 \%$ of the respondents were both smoker and alcoholic and $20.8 \%$ were only smoker. Single alcoholic without smoking habit were $6.2 \%$ (Fig-2).

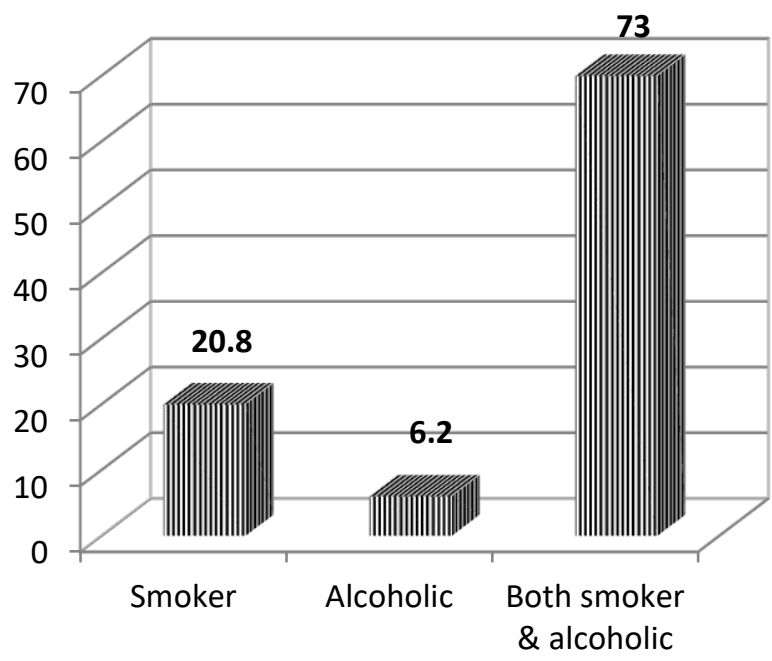

Figure 2: Distribution by personal habit

Among the total 192 respondents, $78(40.6 \%)$ had a working experience of 16-21 years followed by 62 (32.3\%) had $10-15$ years and $52(27.1 \%)$ had $4-9$ years (Table- 1).

Table 1: Distribution of length of working experience

\begin{tabular}{|l|c|c|}
\hline Length in year & Frequency & Percentage (\%) \\
\hline $4-9$ & 52 & 27.1 \\
\hline $10-15$ & 62 & 32.3 \\
\hline $16-21$ & 78 & 40.6 \\
\hline Total & 192 & 100.0 \\
\hline
\end{tabular}

Almost $80 \%$ of the respondents (152 in number) worked for 8 hours and $<8$ or $>8$ hours comprised $10 \%$ each. Seventy-nine percent of the respondents (152) had no depressive symptoms but $21 \%$ had it (40) (Fig$3)$.

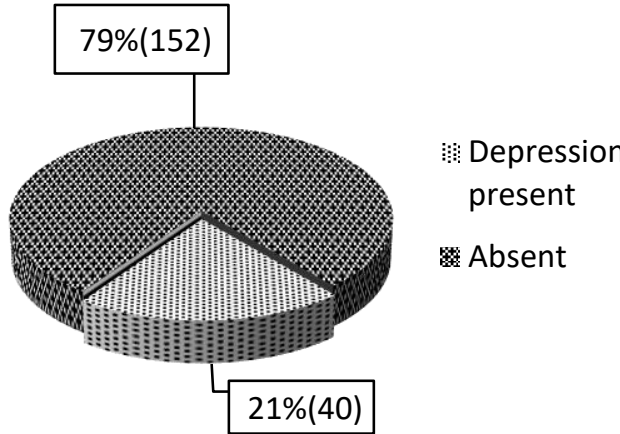

Figure 3: Distribution of garden workers having depression

The result of the Table- 2 shows that $26 \%$ tea garden workers scored more than 2 in GHQ which indicates mental problems and $74 \%$ scored less than 2 who were normal.

Table 2: Distribution of respondents in relation to GHQ score

\begin{tabular}{|c|c|c|c|}
\hline \multicolumn{2}{|c|}{ GHQ>2 } & \multicolumn{2}{c|}{ GHQ<2 } \\
\hline Number & Percentage & Number & Percentage \\
50 & $26.0 \%$ & 142 & $74.0 \%$ \\
\hline
\end{tabular}

The workers who scored more than 2 and qualified the DSM-IV criteria are diagnosed as a positive cases and who scored less than 2 in GHQ but does not qualify DSM-IV, diagnostic criteria are considered as a negative case (Table-3).

Table-3: Distribution of respondents according to DSM-IV who scored >2 in GHQ

\begin{tabular}{|c|c|c|}
\hline & Qualifies DSM-IV & Does not qualify \\
\hline GHQ>2 & 40 & 10 \\
\hline GHQ<2 & 00 & 142 \\
\hline Total & $\mathbf{4 0}$ & $\mathbf{1 5 2}$ \\
\hline
\end{tabular}


Majority of depressive patients has mild depressive disorder and no cases were found suffering from severe depressive disorder (Table-4).

Table 4: Distribution of severity of depression among the diagnosed tea garden workers.

\begin{tabular}{|c|c|c|c|}
\hline No. of cases & Scoring & Severity & Percentage \\
\hline $\mathbf{2 2}$ & $7-17$ & Mild & $55.0 \%$ \\
$\mathbf{1 8}$ & $18-24$ & Moderate & $45.0 \%$ \\
$\mathbf{0}$ & $>24$ & Severe & - \\
\hline
\end{tabular}

There was a significant relationship between gender vulnerable (Table-5). and depression (MDD). Females were more

Table 5: Sex distribution of the respondents by depression (MDD)

\begin{tabular}{|l|c|c|c|c|c|}
\hline \multirow{2}{*}{ Gender } & \multicolumn{2}{|c|}{ MDD present } & \multicolumn{2}{c|}{ Absent } & \multirow{2}{*}{ Significance } \\
\cline { 2 - 5 } & $\begin{array}{c}\text { Number } \\
(\mathbf{n = 4 0 )}\end{array}$ & $\%$ & $\begin{array}{c}\text { Number } \\
(\mathbf{n = 1 5 2})\end{array}$ & $\%$ & \\
\hline Male & 16 & 40.0 & 56 & 36.9 & $\chi^{2}=3.960 \quad \mathrm{p}$ \\
Female & 24 & 60.0 & 96 & 63.1 & \\
Total & 40 & 100.0 & 152 & 100.0 & \\
\hline
\end{tabular}

The table-6 shows that majority of the respondents experience of 16-21 years. with mild depressive disorder had job

Table 6: Distribution of the respondents by job experience and depression (MDD)

\begin{tabular}{|l|c|c|c|c|}
\hline \multirow{2}{*}{ Experience in years } & \multicolumn{2}{|c|}{ MDD present } & \multicolumn{2}{c|}{ Absent } \\
\cline { 2 - 5 } & Number & & Number \\
& $(\mathbf{n}=\mathbf{4 0})$ & $\%$ & $(\mathbf{n}=152)$ & \% \\
& 10 & 25.0 & 42 & 27.6 \\
$\mathbf{4 0 - 1 5}$ & 12 & 30.0 & 50 & 32.9 \\
$\mathbf{1 6 - 2 1}$ & 18 & 45.0 & 60 & 39.5 \\
Total & 40 & 100.0 & 152 & 100.0 \\
\hline
\end{tabular}

Almost all the respondents who had to work for more than or equal to 8 hours were suffering from depression and none of the workers worked $<8$ hours were fell in this category (Table-7). 
Table 7: Distribution of the respondents by duration of working hour and depression

\begin{tabular}{|c|c|c|c|c|}
\hline \multirow{2}{*}{ Duration of working hour } & \multicolumn{2}{|c|}{ MDD present } & \multicolumn{2}{c|}{ Absent } \\
\cline { 2 - 5 } & $\begin{array}{c}\text { Number } \\
(\mathbf{n = 2 0})\end{array}$ & $\mathbf{\%}$ & $\begin{array}{c}\text { Number } \\
(\mathbf{n = 7 6 )}\end{array}$ & $\%$ \\
\hline$<\mathbf{8}$ & 0 & - & 20 & 13.2 \\
$\mathbf{8}$ & 20 & 50.0 & 132 & 86.8 \\
$>\mathbf{8}$ & 20 & 50.0 & 0 & - \\
Total & 40 & 100.0 & 152 & 100.0 \\
\hline
\end{tabular}

\section{DISCUSSION}

This is a cross sectional type of descriptive study. The aim of this study was to find out the proportion of workers having depression and related factors in Jaflong tea garden in Goainghat, Sylhet among 192 respondents. The workers were at first screened by screening tool of General Health Questionnaire $12^{6}$ and then who scored more than 2 were clinically assessed by DSM-IV ${ }^{7}$ criteria which is subsequently confirmed by consultant psychiatrist. After then Hamilton Rating scale for depression (HRDS) ${ }^{8}$ was used to measure the severity of depression among the diagnosed depressed cases.

It has been evident that the overall depressive disorder among general population is $10 \%$ to $20 \%$ worldwide. ${ }^{9}$ In Bangladesh, $4.6 \%$ has major depressive disorder among general population ${ }^{15}$. So definitely working people will face more depression then general population by its nature. In this study the proportion of major depressive disorder is $21 \%$ which is highly significant. It also correlates with other studies done in Bangladesh among garment workers where it is $15.1 \%$ and $13.6 \%$ and $9.8 \% . .^{10,11,12}$

The respondents were ranged from 20 to 50 years with the mean age of 34.76 years. Out of 192 respondents 72 were male $(37 \%)$ and 120 were female $(63 \%)$. The females were more encouraged to work. ${ }^{12}$ Regarding sex majority result was significant and female were more vulnerable. A study showed women experience higher rates of depression than men with estimates that women experience depression 2 to 3 times more than men. ${ }^{13}$ More than half of the respondents were married $(65.6 \%)$ and married person found more depressed than unmarried person and result highly statistically significant. Married persons are more concerned about their own future and the uncertainly of their relatives, spouses and offspring. This is also similar with studies. ${ }^{10,12}$ About four-fifth (80\%) of the respondents were illiterate and rest $20 \%$ respondents were educated up to primary level education.
Regarding level of income among the tea garden workers more are found in low income group $(<2000$ TK. Month) and the result is not statistically significant. This is also fact that they worked hard but paid less. So within this income they have to maintain their livelihood. This finding is also correlates with other studies. ${ }^{12,16}$

Among the total 192 respondents, $78(40.7 \%)$ had a working experience of 16-21 years followed by 62 (32.3\%) had 10-15 years and $52(27 \%)$ had $4-9$ years. Almost $80 \%$ of the respondents (152 in number) worked for 8 hours and $10 \%$ of the respondents claimed that they had to work $<8$ hours and another $10 \%$ of the respondents claimed that they had to work $>8$ hours. Seventy nine percent of the respondents (152) had no depressive symptoms but twenty one percent had it (40). Among them 26\% tea garden workers scored more than 2 in GHQ which indicates mental problems and $74 \%$ scored less than 2 who were normal. According to WHO, the number of mentally ill people in Bangladesh is about 8.4 million i.e., $7 \%$ of the population of 120 million. ${ }^{14}$ In a study done on industrial workers in India using GHQ12 the prevalence was found to be $51.7 \%$. ${ }^{17}$ A community based study in Western Nigeria using GHQ12 found the same to be $18.9 \%$. ${ }^{18}$ Altogether 40 respondents were found as patient of depression and the prevalence rate was more in ever married women of less than or equal to 35 years old and whose experience was 16-21 years and have to work more than or equal to 8 hours. In a study done by Dutta ${ }^{19}$ on industrial workers, educational level, perceived stress, job satisfaction and stressful life events were identified as the independent determinants of psychiatric morbidity. However, in this study, statistically significant association found between the prevalence of probable mental illness and gender, age, education, occupation, socio-economic status, marital status, type of family, stressful life events and job or salary satisfaction. 


\section{CONCLUSION}

Many hidden cases of depression remain in both the general and various working group populations. The present study found a sensitive proportion of tea garden workers having depression. The prevalence rate was significantly more in ever married women of less than or equal to thirty-five years old and whose had long experience of work and had to work more than or equal to eight hours per day. The study recommends that depression is a significant public health problem in particular occupational group like tea garden workers and it demands special attention and addressing effective measures by concerned authority and stakeholders.

\section{REFERENCES}

1. Living condition of the tea workers and SAARC social charter, http://rasheeka.worldpress.com; February 5, 2009. Download on June 16, 2010 at $1: 20 \mathrm{pm}$.

2. Canadian Mental Health Association. Workplace Health: Depression in the workplace. www.peel region, ca;2008.

3. Philip T. Depression in the workplace. Royal College of Psychiatrist's Public education editorial board,Oct. 2006.

4. Rolt F, Jones D. Relationship of tea worker with managers. Bangladesh Tea Board, Banglapedia. October 9, 2008.

5. Simon H. Depression. J. of Ame Psychiatric 2006. ADAM ( www.urac.org.)

6. General Health Questionnaire-12. Health Qual. Life outcomes, 2003; 1:60.

7. American Psychiatric Association. Diagnostic and Statistical Manual of Mental Disorders, $4^{\text {th }}$ ed. Washington DC, 1994.

8. Hamilton Depression Rating Scale. http://www.mind disorders. Comp/flu-4/ Hamilton, Depression-Scale.html,2007.
9. Firoz AHM. Manual of mental health for primary health care physicians. WHO and NIMH, $2^{\text {nd }}$ edn, 2007;118.

10. Ara N. Psychiatric morbidity among the female garment workers of Dhaka city, IPGMR,1993; 17.

11. Khan MH. Prevalence of Depressive and anxiety disorders among the workers in some selected garment factories of Dhaka city. NIPSOM, 2000.

12. Chowdhury NS. Depression among workers in selected garment factories. NIPSOM, 2008.

12. Hankin A, Abramson H. Development of gender differences in depression: Description and possible explanations. Ann of Med, 1999; 31: 372-79.

13. Society for Women's Health Research. Mental Health. Retrieved from Society for Women's Health Research, http://www.womenshealthresearch.org/site; November 30, 2007.

14. Firoz AHM. Manual of mental health for primary health care physicians. WHO and NIMH, $2^{\text {nd }}$ edn, 2007;118.

15. Hosain GM, Chatterjee N, Ara N, Islam T. Prevalence, pattern and determinants mental disorders in rural Bangladesh. J. of public health, 2007;121(1): 18-24.

16. Dutta S, Kar N, Thirthalli J, Nair S. Prevalence and risk factors of psychiatric disorders in an industrial population in India. Indian J Psychiatry 2007; 49:103-8.

17. Anwar Khan, Subhan Ullah, Kamran Azam, Dr. Salim Khan. Individual differences and mental health disorders among industrial workers: A cross sectional survey of Hayatabad Industrial Estate Peshawar, Pakistan. International Review of Business Research Papers (IRBRP), (6), 3039.

18. Kar N, Dutta S, Patnaik S. Mental health in an Indian industrial population: Screening for psychiatric symptoms. Indian J Occup Environ Med. 2002; 6:86-8. 